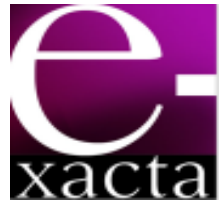

ISSN: 1984-3151

\title{
O EMPREgo dA TECNOLOGIA LED NA ILUMINAÇÃO PÚBLICA
}

\author{
The Use of LED Technology IN StReet Lighting
}

\author{
Ana Cristina Cota Ribeiro'; Helbert Carlos Pinto Rosa²; \\ Joana D'Arque da Silva Correa ${ }^{3}$; Arlete Vieira da Silva ${ }^{4}$
}

1 Graduanda em Engenharia Elétrica do Centro Universitário de Belo Horizonte - UniBH, 2012. Belo Horizonte, MG. Yazaki Automotive Products. Pedro Leopoldo, MG. anicota1@hotmail.com.

2 Graduando em Engenharia Elétrica do Centro Universitário de Belo Horizonte - UniBH, 2012. Belo Horizonte, MG. Anglogold Ashanti Brasil. Sabará, MG. helbertcarlos@hotmail.com

3 Mestre em Engenharia Elétrica. PUC - MG, 2001. Professora de Máquinas Elétricas e Acionamentos Elétricos, Centro Universitário de Belo Horizonte - UniBH. Belo Horizonte, MG. joana.correa@profunibh.br

4 Mestre em Geografia e Análise Ambiental; IGC/UFMG 2002. Professora de Trabalho de Conclusão de Curso, Centro Universitário de Belo Horizonte - UniBH. Belo Horizonte, MG. arlete.silva@prof.unibh.br

Recebido em: 29/05/2012 - Aprovado em: 10/07/2011 - Disponibilizado em: 30/12/2012

RESUMO: Este trabalho tem como objetivo concentrar estudos e soluções baseadas em novas tecnologias e novos conceitos a serem implementados em iluminação pública, visando a redução no consumo de energia elétrica. A economia de energia elétrica é um assunto de grande importância, pelo fato do País se aproximar de uma possível crise energética. As tecnologias que foram estudadas são baseadas em LEDs de alto brilho, aplicadas à iluminação pública, que tem por objetivo avaliar uma possível substituição da luminária com lâmpada vapor de mercúrio $125 \mathrm{~W}$ por um modelo de luminária a LED. Foram realizadas pesquisas baseadas em catálogos de diversos fabricantes e ensaios luminotécnicos para obtenção de informações técnicas, visando atingir níveis satisfatórios de economia e qualidade na iluminação pública. As luminárias de tecnologia a LEDs já são uma realidade em alguns países e com grandes chances de serem aplicadas em outros. Mas para que haja êxito na sua implantação, devem ser analisados diversos fatores, os quais serão abordados no decorrer deste trabalho. Palavras-chave: LED, luminotécnica, iluminação pública, eficiência energética.

ABSTRACT: The job has as target to concentrate the studies and solutions based in new technologies and new concepts of public illumination to be implemented, always having electric energy saving as a goal. Considering that our country is near of an energetic shortage, reducing the waste of electric power is such an important issue. The technologies that have been studied are based in high brightness LEDs, having as objective to compare and to 
decide whether or not a LED luminary is a feasible substitution for the lamp mercury steam 125Watts. To obtain the needed technical information, a lot of research was done on several manufacturers catalogs and lighting tests, hoping to reach satisfactory levels of economy and quality in public illumination. The LED technology luminaries have been used in a few countries and they have very good prospects of being implemented in other countries as well. In order for this implementation to be real, a lot of factors must be analyzed. They will be addressed in this study.

Keywords - LED, luminotecnics, public Illumination, energy efficiency.

\section{INTRODUÇÃO}

Os sistemas de iluminação vêm passando nas últimas duas décadas por profundos avanços, em especial aqueles relacionados ao emprego da eletrônica nos processos de ignição, acionamento e promoção da eficiência energética. Nos últimos dez anos, um novo conceito em iluminação tem se estabelecido de forma progressivamente inequívoca. Trata-se do emprego dos diodos emissores de luz, ou LEDs (light emitting diodes), para constituir sistemas de iluminação destinados ao ambiente doméstico, comercial, industrial ou externo (público).

A utilização de materiais semicondutores para gerar luz apresenta-se como uma alternativa recente. Nestes materiais, a luz é emitida através da recombinação de elétrons e lacunas em excesso que são produzidos por injeção decorrente com pequenas perdas de energia.

De acordo com Schubert (2003), este fenômeno é conhecido como eletroluminescência sendo a base de funcionamento de todos os LEDs. Os atuais LEDs geralmente emitem baixos níveis de radiação infravermelha ou ultravioleta.

Os LEDs foram, durante várias décadas, empregados com a única função de indicar o estado de funcionamento de produtos eletroeletrônicos. Mais recentemente, também foram usados como elementos sinalizadores (lâmpadas de emergência, semáforos etc.). O seu emprego na iluminação de ambientes internos ou externos é, entretanto, muito recente.
Um dos grandes benefícios que possivelmente decorrerá da utilização em larga escala de dispositivos de estado sólido para a iluminação geral é a diminuição do consumo de energia. De acordo com o livro de TSAO, cerca de $50 \%$ da energia consumida com iluminação poderia ser poupada com a utilização de iluminação de estado sólido em todo o mundo, o que representaria um decréscimo de mais de $10 \%$ no consumo total de energia.

Além da redução do consumo de energia está a questão ambiental, uma vez que grande parte da energia elétrica produzida no mundo é proveniente da queima de combustíveis fósseis como o carvão e o petróleo. Assim, a redução no consumo de energia elétrica pode estar diretamente ligada à redução da emissão de poluentes na atmosfera. Outro ponto importante relacionado ao ambiente é o emprego de elementos químicos pesados, como por exemplo o mercúrio, na construção de lâmpadas de descarga. Tais elementos não são usados em lâmpadas com LEDs.

Logo, o trabalho tem por objetivo realizar um estudo a respeito do aumento da eficiência energética da iluminação pública, apresentando as vantagens de um sistema de baixo consumo de energia.

Para tal, foram especificados os seguintes objetivos:

- Levantamento das tecnologias de iluminação utilizadas atualmente.

- Pesquisa bibliográfica sobre o consumo dos sistemas de iluminação pública atuais. 
- Estudo e compreensão da tecnologia LED, para aplicação em sistemas de iluminação pública.

- Propor um sistema de implantação de luminárias LED para uma empresa de mineração.

- Demonstrar as vantagens de ter um sistema de iluminação baseado na tecnologia LED.

Vale ressaltar que este artigo, trata-se de um estudo de caso, realizado em uma empresa privada, onde trabalha um dos autores, portanto, os resultados, fotos e tabelas aqui encontrados, apesar de serem coletados pelos autores, pertencem agora à empresa, onde foram instaladas as luminárias.

\section{Dispositivos de IluminAçÃo}

Ao longo dos tempos, o aumento das necessidades de iluminação foi originando o desenvolvimento de tecnologias de suporte cada vez mais eficazes. Para além da sua eficiência, outros aspectos foram considerados no desenvolvimento destes sistemas, como por exemplo, a utilização em larga escala, a qualidade de iluminação (IRC), a utilização de produtos menos poluentes e o custo de fabricação. No caso de tecnologias para utilização na iluminação pública os requisitos mudam um pouco de contexto. A qualidade da iluminação é muitas vezes colocada à parte em relação à eficiência, tendo em vista, a quantidade de lâmpadas necessárias. Em geral, a maior parte das luminárias instaladas atualmente não dispõe de disparo imediato, nem possibilidade de controle do fluxo luminoso; o que por si só constitui largos gastos com a iluminação.

A próxima seção é iniciada com uma breve abordagem às unidades de fotometria, pelas quais todos os sistemas são comparados em termos de desempenho, além das grandezas elétricas. Em seguida serão apresentadas as tecnologias de suporte aos sistemas de iluminação que foram desenvolvidas, ao longo da história da humanidade, assim como, as suas principais vantagens e desvantagens. Será feita também, uma introdução à história e composição do LED (Light Emitting Diode), bem como o seu princípio de funcionamento.

\subsection{UNIDADES DE FOTOMETRIA}

No estudo de sistemas de iluminação pública é necessário ir muito além da eficiência e qualidade de iluminação. Uma das métricas de projeto mais importante relaciona-se com os níveis legais de iluminação, aos quais o sistema é condicionado antes de ser possível a sua comercialização e distribuição. Neste sentido, os métodos de caracterização necessitam de grandezas que permitam quantificar a qualidade da iluminação. As unidades do SI (sistema internacional) de fotometria são em seguida explicadas em termos físicos, conforme o artigo de MINOLTA (2002).

\section{Intensidade Luminosa}

Se a fonte luminosa irradiasse a luz uniformemente em todas as direções, o Fluxo Luminoso se distribuiria na forma de uma esfera. Tal fato, porém, é quase impossível de acontecer, razão pela qual é necessário medir o valor dos lumens emitidos em cada direção. Essa direção é representada por vetores, cujo comprimento indica a Intensidade Luminosa. Em outras palavras é a potência da radiação luminosa em uma dada direção.

\section{Fluxo Luminoso}

É a potência de radiação total emitida por uma fonte de luz em todas as direções do espaço e capaz de produzir uma sensação de luminosidade através do estímulo da retina ocular. Em outras palavras, é a 
potência de energia luminosa de uma fonte percebida pelo olho humano.

\section{Iluminância (Iluminamento)}

É a relação entre o fluxo luminoso incidente numa superfície e a superfície sobre a qual este incide; ou seja, é a densidade de fluxo luminoso na superfície sobre a qual este incide. A relação é dada entre a intensidade luminosa e o quadrado da distância, ou ainda, entre o fluxo luminoso e a área da superfície, conforme a Eq. 1:

$$
E=\Phi / A
$$

onde: $E$ = lluminância $[\mathrm{Lx}], \Phi=$ Fluxo Luminoso $[\mathrm{Lm}]$, $\mathrm{A}=$ Área $\left[\mathrm{m}^{2}\right]$.

\section{Luminância}

É um dos conceitos mais abstratos que a luminotécnica apresenta. É através da luminância que o homem enxerga. No passado denominava-se de brilhança, querendo significar que a luminância está ligada aos brilhos. A diferença é que a luminância é uma excitação visual, enquanto que o brilho é a resposta visual. A luminância é quantitativa e o brilho é sensitivo, conforme a Eq. 2:

$$
\mathrm{L}=\mathrm{I} / \mathrm{A} \text {. Cos } \mathrm{a}
$$

onde: $\mathrm{L}=$ Luminância $\left[\mathrm{Cd} / \mathrm{m}^{2}\right], \mathrm{I}=$ Corrente $[\mathrm{A}], \mathrm{A}=$ Área $\left[\mathrm{m}^{2}\right]$, Cos $=$ Fator de Potência.

Na Figura 1 encontram-se definidas de uma forma gráfica algumas das grandezas mais importantes das unidades de Fotometria.
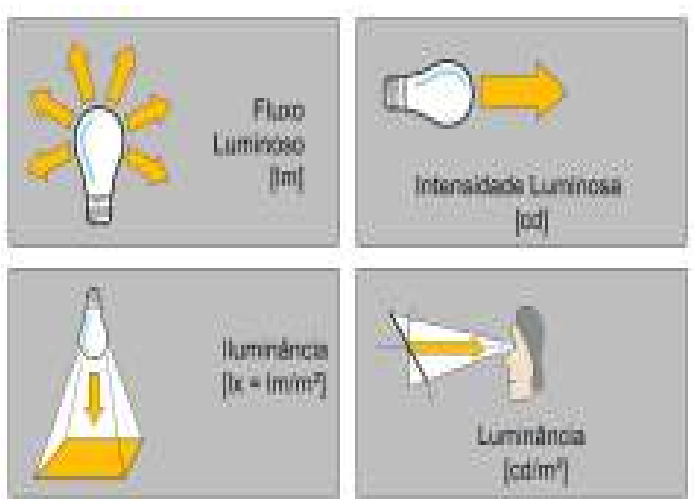

Figura 1: Ilustração das grandezas de Fotometria. Fonte: MINOLTA, 2002.

\subsection{ESTUDO COMPARATIVO SOBRE DISPOSITIVOS DE ILUMINAÇÃO}

Basicamente, existem três grupos de dispositivos, sendo eles: incandescência, descarga de gases e iluminação de estado sólido (SSL) recorrendo a semicondutores, esta última bastante recente. $\mathrm{Na}$ Figura 2 estão representados sob a forma de esquema os dispositivos de iluminação, bem como as suas inter-relações.

De uma forma muito breve, pode-se caracterizar cada um dos grupos primários pela sua natureza de operação. As lâmpadas de incandescência funcionam recorrendo ao efeito de Joule. Quando se faz passar uma corrente elétrica num filamento, o seu aquecimento cria radiação na gama do visível.

Outra tecnologia depende da descarga de um gás entre dois eletrodos que excitam um pó fluorescente. Dentro deste grupo existem muitas formas de realizar essa descarga, bem como diversos elementos fluorescentes possíveis de serem utilizados. 


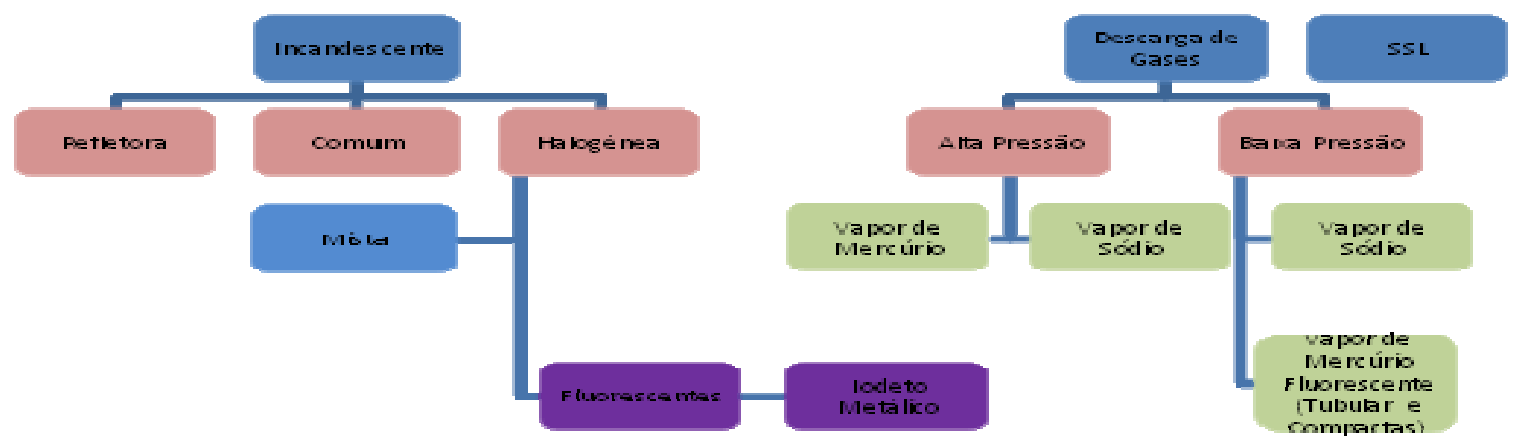

Figura 2: Diagrama expositivo das várias tecnologias de iluminação. Fonte: SANTOS, 2005.

Por fim, e mais recentemente, descobriu-se a iluminação com recurso a LEDs. Estes baseiam o seu princípio de funcionamento, no efeito da passagem de uma corrente elétrica através de uma junção PN com uma camada ativa. A interação dos elétrons ao atravessarem a camada de valência, pela imposição de uma diferença de potencial, liberta fótons criando um feixe luminoso. Este efeito pode ser adaptado para emitir sob a forma de luz branca. Algumas das características mais importantes das fontes luminosas que recorrem à tecnologia semicondutora são: a elevada eficiência e a elevada longevidade.

Embora algumas destas tecnologias estejam ultrapassadas, são aqui referidas, dado que todas elas ainda são utilizadas, sejam em aplicações mais específicas, seja de uso geral.

\subsection{1 ÍNDICE DE REPROdUÇÃo de CORES}

Outra das principais métricas de comparação é o IRC (Índice de Reprodução Cromática), este valor pode variar entre 0 e 100, conforme a radiação da fonte luminosa se distribui, menos ou mais, na gama do visível. Quanto mais componentes espectrais uma fonte luminosa contiver na sua radiação, melhor será para o olho humano distinguir as diversas cores, na sua presença. Deste modo, quanto maior o IRC, melhor.

Nos gráficos da Figura 3, estão representadas as intensidades relativas do fluxo luminoso emitido por diversos tipos de lâmpadas em função do comprimento de onda na gama do visível.

Existem dois gráficos de lâmpadas fluorescentes e dois gráficos de lâmpadas de iodetos metálicos, ambos se devem a naturezas construtivas distintas. $O$ IRC será tanto melhor, quanto maior for a distribuição de intensidade ao longo de todo o espectro, como dito anteriormente. De fato, observa-se que algumas das lâmpadas têm um IRC tão baixo que leva a que seja difícil ou quase impossível, ao olho humano, distinguir as cores em ambientes iluminados por fontes de luz desse tipo.

Um caso extremo é o das lâmpadas de vapor de sódio de baixa pressão, que emitem um feixe luminoso amarelo, fazendo com que tenham uma reprodução de cores muito fraca. Contudo, são as fontes luminosas que apresentam maior eficiência, podendo ser úteis em algumas situações.

e-xacta, Belo Horizonte, v. 5, n. 1, p. 111-132. (2012). Editora UniBH. Disponível em: www.unibh.br/revistas/exacta/ 

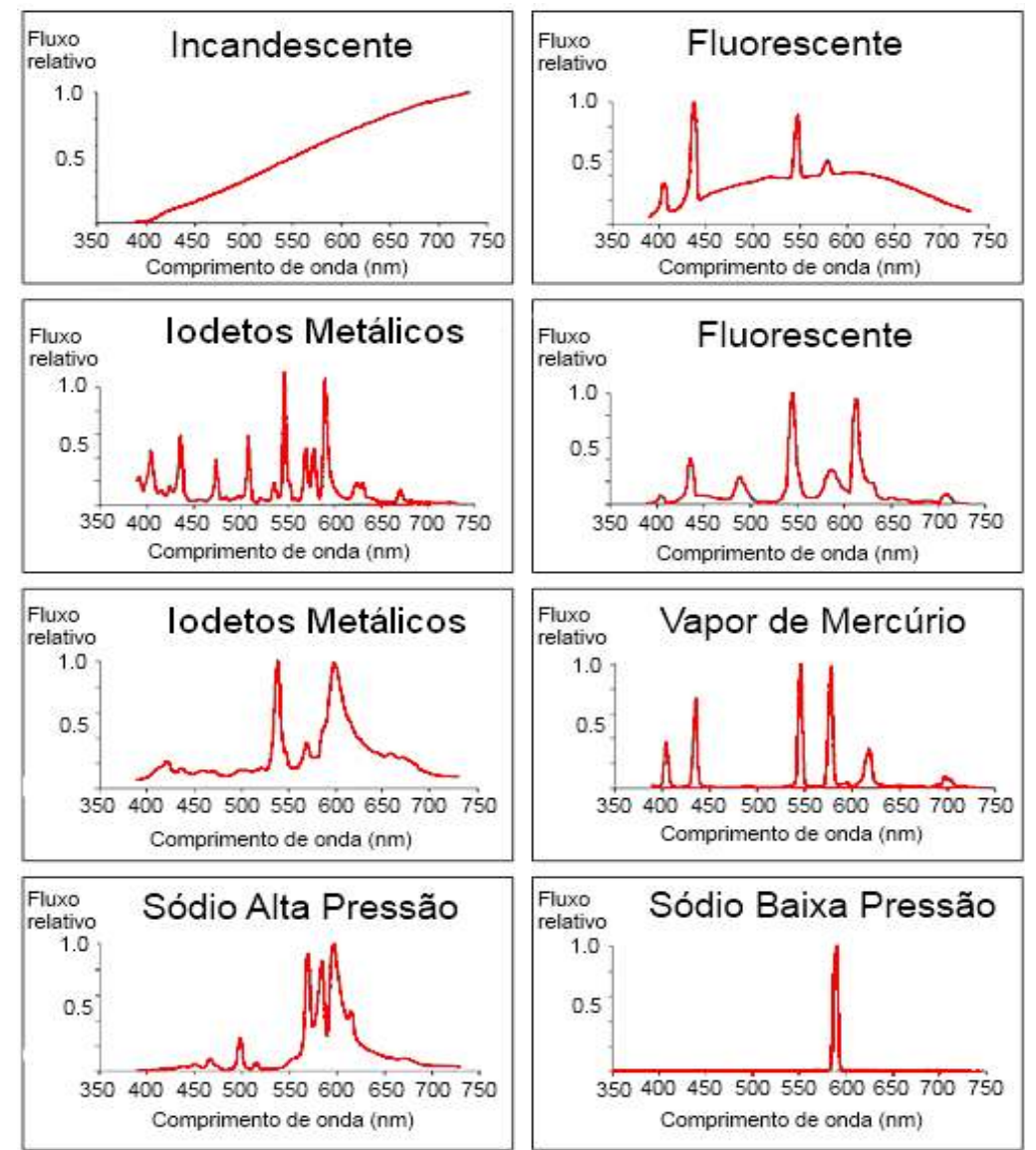

Figura 3: Potência relativa do fluxo luminoso em função do comprimento de onda de vários tipos de Lâmpadas. Fonte: NEARY; QUIJANO, 2009.

\subsection{A Tecnologia Led Comparada com OUTRAS TECNOLOGIAS}

Segundo Gianelli et. al. (2009), a qualidade e a eficiência energética são alguns dos pontos centrais de pesquisa e melhoramento de muitas concessionárias de energia elétrica, sendo que o emprego de tecnologia LED, principalmente no que diz respeito à iluminação pública, pode vir a contribuir significativamente na melhoria desses resultados.

A evolução da tecnologia LED, conforme apresentada na Figura 4, iniciou-se em 1961 com um diodo emissor de infravermelho, sendo que em 1962 a tecnologia LED foi empregada pela primeira vez para emissão de luz visível; na década de 70 a mesma passou a ser comercialmente viável, sendo que os primeiros LED's de alta luminosidade (HB LED) foram desenvolvidos nos anos 80; os LED's de luz azul, ou "cool LED's" foram desenvolvidos em 1993 e os "Power LED's" entram no mercado já no século $X X I$, sendo que em alguns estudos sua potência já alcançou patamares de $50 \mathrm{~W}$, de acordo com pesquisa no site da Eletrobrás (2011).

Zukauskas, Shur e Gaska (2002) afirmam que os componentes básicos de uma lâmpada LED são: lente plástica protetora; eletrodo, fio de ouro e conexão; dissipador de calor; silicone para proteção contra descargas eletrostáticas e o chip LED (Figura 5). 


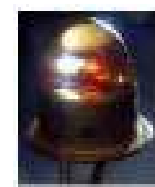

60 's

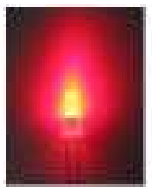

70 's

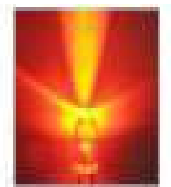

80 's

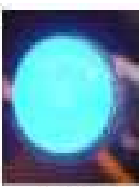

90 's

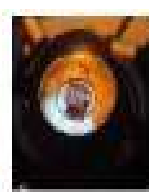

2000
Figura 4. Evolução da tecnologia das lâmpadas LED's.

Fonte: BRABER, 2007.

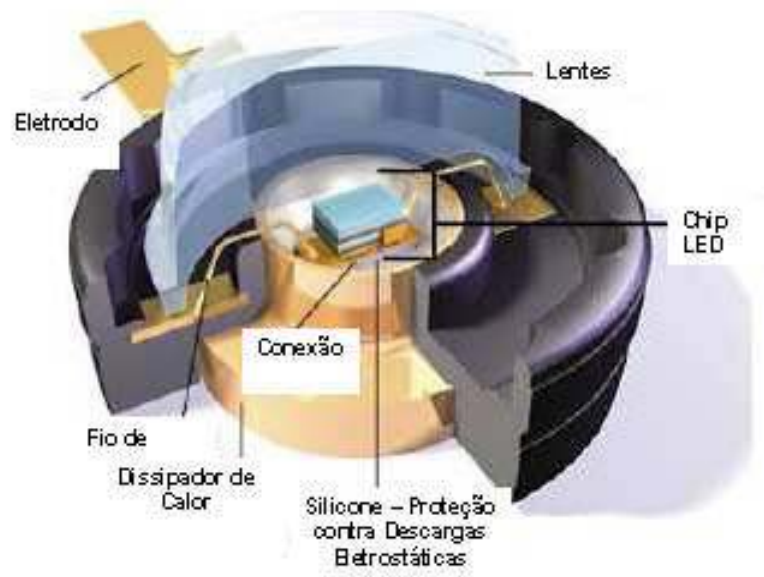

A Figura 6 evidencia claramente a evolução da tecnologia em comparação a outras já existentes no mercado e também deixa claro suas limitações atuais. Os "Power LED's" de luz visível já se tornaram competitivos, em termos de eficiência luminosa, se comparados a lâmpadas incandescentes, halógenas e de mercúrio, no entanto, ainda distam significativamente das lâmpadas de fluorescentes e de multi-vapores metálicos. Embora o emprego da tecnologia LED ainda possua alguns desafios a serem vencidos, principalmente no que diz respeito ao seu alto custo inicial e na regulamentação de sua fabricação, a mesma apresenta grandes vantagens, tais como a qualidade de sua luz e sua eficiência energética segundo Schubert (2003).

Figura 5. Componentes básicos de um LED. Fonte: HANSALER, 2007.

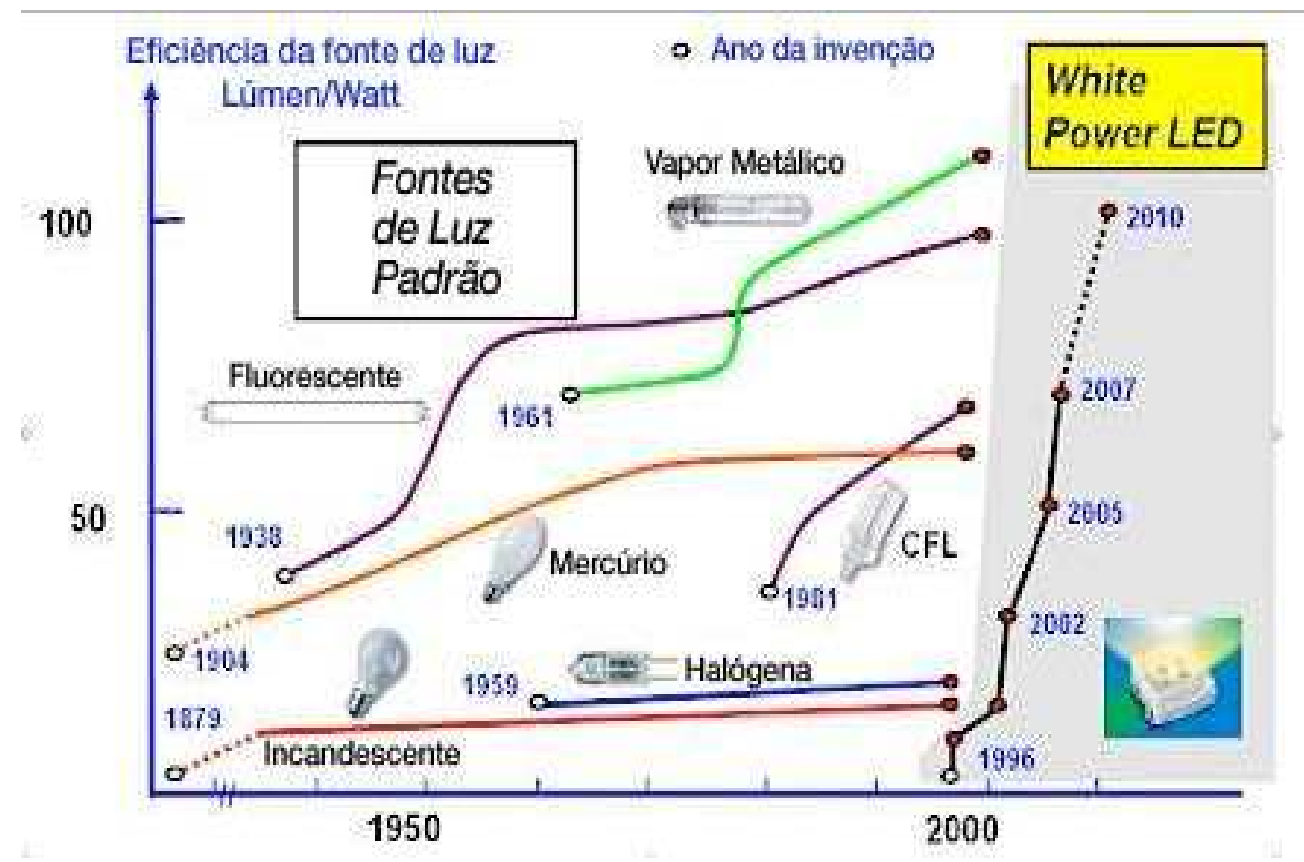

Figura 6. Comparativo de eficiência luminosa entre os "PowerLED's" e outras tecnologias.

Fonte: MAGHE, 2007. 
Essa mesma eficiência energética é denotada em um estudo comparativo entre uma lâmpada HID e um LED de luz visível (Figura 7), por esse estudo é possível notar que para a mesma eficiência de iluminação faz- se necessário uma capacidade luminosa por potência maior na lâmpada HID, se comparada ao LED, segundo pesquisa no site da Eletrobrás (2012).

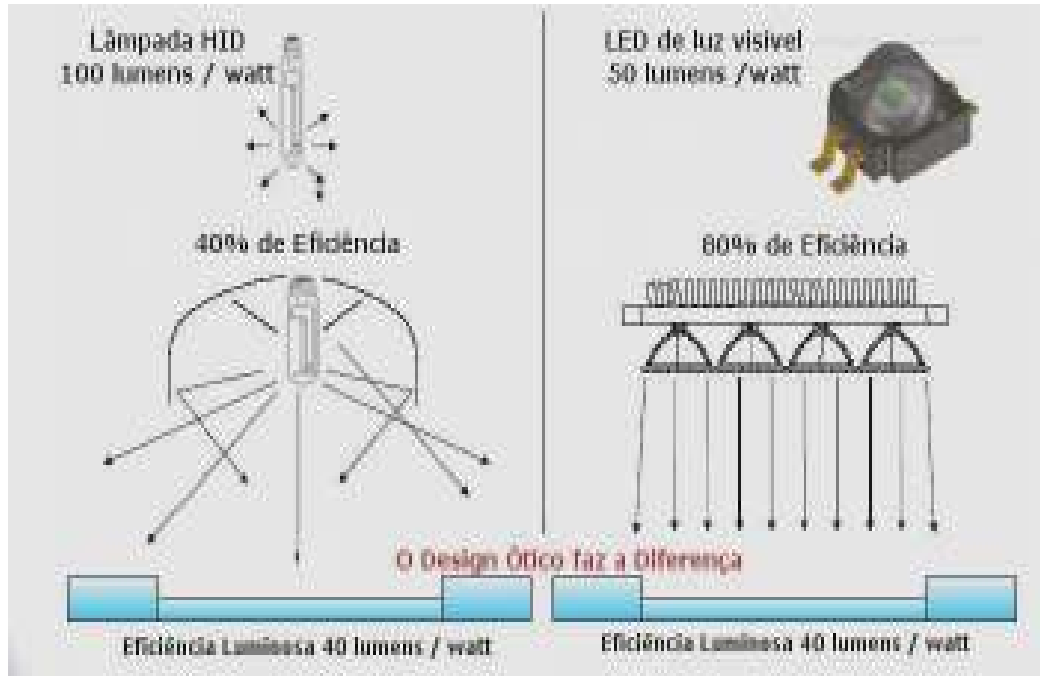

Figura 7. Comparativo de eficiência luminosa entre os "Power LED's" e outras tecnologias.

Fonte: MAGHE, 2007.

De acordo com Resende (2004), isso se deve ao processo de espalhamento que ocorre nas lâmpadas convencionais empregadas na iluminação pública, pelo qual parte da luz emitida não é direcionada para a principal região a ser iluminada (Figura 8), causando assim uma poluição luminosa.

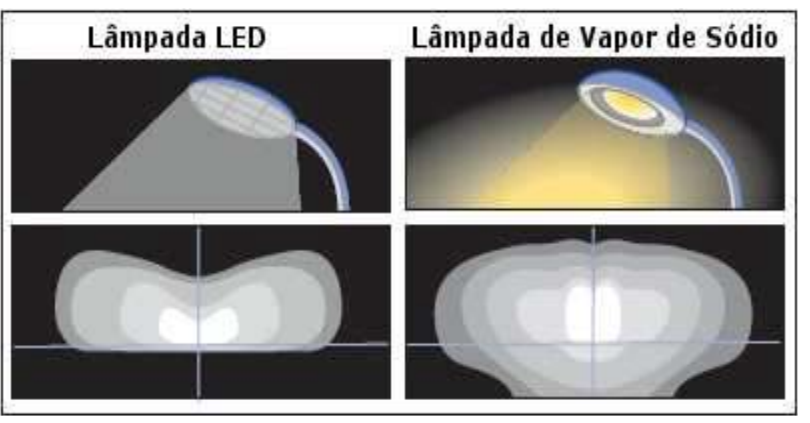

Figura 8 - Espalhamento entre lâmpadas LED's" e outras tecnologias.

Fonte: WHITAKER, 2006.

\section{ILUMINAÇÃo PÚBLICA}

A lluminação Pública (IP) é o serviço que vem prover luz ou claridade artificial nos logradouros públicos. Este serviço tem influência direta na vida de todo cidadão, uma vez que contribui para a segurança da população, para o tráfego de veículos e viabiliza atividades de comércio, turismo, lazer, etc. (CASA; VERONI, 1999).

A Tabela 1 mostra as quantidades e os tipos de lâmpadas utilizados na iluminação pública no Brasil nos anos de 1995 e 2008. Observa-se o aumento da quantidade de lâmpadas de vapor de sódio em alta pressão (VSAP). Isto devido à alta eficácia luminosa atribuída a este tipo de lâmpada. Tradicionalmente, tem-se utilizado lâmpadas de descarga em alta intensidade (HID - do inglês High Intensity Discharge) para a iluminação pública (mais de 95\% do total em 
2008). Isto ocorre devido ao alto fluxo luminoso e à elevada vida útil característicos destas lâmpadas.

Tabela 1

Lâmpadas utilizadas na iluminação pública no Brasil

\begin{tabular}{c|cc}
\hline \multirow{2}{*}{ Tipo de Lâmpada } & \multicolumn{2}{|c}{ Percentual } \\
\cline { 2 - 3 } & $1995[2]$ & $2008[3]$ \\
\hline Vapor de Sódio & $7,3 \%$ & $62,93 \%$ \\
\hline Vapor de Mercúrio & $80,7 \%$ & $31,84 \%$ \\
\hline Mista & $7,0 \%$ & $2,22 \%$ \\
\hline Incandescente & $3,8 \%$ & $1,42 \%$ \\
\hline Fluorescente & $1,2 \%$ & $0,81 \%$ \\
\hline Multi-Vapores & - & \\
\hline Metálicos & & \\
\hline Total de Unidades & 8.782 .000 & $0,03 \%$ \\
\hline Instaladas & & \\
\hline
\end{tabular}

Fonte: ELETROBRAS, 2008.

Segundo levantamento realizado pelo PROCEL I ELETROBRAS no ano de 2008, a iluminação pública no Brasil correspondia a aproximadamente $4,50 \%$ da demanda nacional e a $3,00 \%$ do consumo total de energia elétrica do país, ou seja, o equivalente a uma demanda de 2,2 GW e a um consumo de 9,7 bilhões de kWh/ano. Neste mesmo levantamento, constatouse que havia aproximadamente 15 milhões de pontos de iluminação pública instalados no país, sendo que a região sudeste concentra a maior quantidade desses pontos de iluminação, cerca de $45 \%$ do total.

\subsection{ANÁLISES AmBIENTAIS}

De acordo com o texto de APLIQUIM, as lâmpadas de vapor de mercúrio apresentam os seguintes impactos negativos no meio ambiente: descarte de mercúrio, emissão de radiação ultravioleta, radiação infravermelha e contribuição com a emissão de $\mathrm{CO}_{2}$ (dióxido de carbono) que é um dos gases que provoca o efeito estufa.

\subsubsection{CONTAMINAÇÃO POR MERCÚRIO}

Ainda de acordo com os mesmos autores, o mercúrio é um metal tóxico e é o único que volatiliza a temperatura ambiente. A lâmpada de vapor de mercúrio contém em média $0,013 \mathrm{~g}$ a $0,080 \mathrm{~g}$ de mercúrio.

A disposição inadequada deste material em lixões, aterros sanitários e outros causam prejuízo ao meio ambiente e ao homem. Ao final da sua vida útil as lâmpadas são, na maioria das vezes, destinadas aos aterros sanitários, contaminando o solo e, mais tarde, cursos d' água.

O vapor de mercúrio em contato com o ar tende a precipitar no solo e na água. Sendo que no solo pode fixar-se em matérias orgânicas (plantas, microorganismos, insetos); pode-se reduzir a sais ou formas orgânicas (extremamente perigosas); na água, mesmo em pequenas quantidades, representa um problema ecológico devido a sua bio-concentração, ou seja, a concentração de mercúrio aumenta nos organismos animais com a passagem através da cadeia alimentar devido ao depósito do metal em vários tecidos vivos. O mercúrio interage com compostos químicos e micro organismo, gerando metil - mercúrio com facilidade, que é a sua forma mais tóxica.

Além do mercúrio a lâmpada ainda contém: estrôncio, bário, ítrio, chumbo e vanádio. De acordo com a NBR

e-xacta, Belo Horizonte, v. 5, n. 1, p. 111-132. (2012). Editora UniBH. Disponível em: www.unibh.br/revistas/exacta/ 
10.004 de 2004, a lâmpada de mercúrio se enquadra como Resíduo Classe I, ou seja, resíduo tóxico (APLIQUIM, 2009).

Levando-se em conta uma quantidade média de 0,047g de mercúrio por lâmpada, a substituição pode evitar que $232,50 \mathrm{~kg}$ de mercúrio cheguem à natureza e que $705 \mathrm{~kg}$ de mercúrio se considerassem a vida útil do LED. De acordo com (APLIQUIM, 2009) o valor para descontaminação da lâmpada vapor de mercúrio por unidade varia de $R \$ 1,00$ a $R \$ 1,20$, fora os custos de transporte. Observando o valor médio de $R \$ 1,10$ o custo de descarte dos 5 milhões de pontos de iluminação pública com lâmpada de vapor de mercúrio seria de $R \$ 5.500 .000,00$ e se pegar o período de 11 anos de vida útil do LED, a LVM seria substituída 3 vezes, e o custo total do descarte dessas lâmpadas seria de $R \$ 16.500 .000,00$.

\subsubsection{RADIAÇÃo ULtRAVIOLETA E INFRAVERMELHA}

Nas lâmpadas de vapor de mercúrio a luz é produzida pela combinação de excitação e fluorescência. A descarga de mercúrio no tubo de arco produz uma energia visível na região do azul e do ultravioleta. O fósforo, que reveste o tubo, converte o ultravioleta em luz visível na região do vermelho (RODRIGUES, 2002). A luz ultravioleta faz parte do espectro eletromagnético, com comprimentos de onda entre 100 e 400 nanômetros (nm). Quanto menor o comprimento de onda, maior a energia produzida.

Os raios ultravioleta, embora invisíveis, são semelhantes à luz visível, e abrangem vários comprimentos de onda e propriedades. UV-A e UV-B fazem parte do espectro ultravioleta e a Tabela 2 mostra a faixa de exposição.
Tabela 2

Comprimento de onda dos raios ultravioleta

\section{Comprimento de Onda Denominação}

$(\mathrm{nm})$

\begin{tabular}{|ll|}
\hline 100 a 280 & UV-C \\
\hline 280 a $315(320)$ & UV-B \\
\hline $315(320)$ a 400 & UV-A \\
\hline
\end{tabular}

Fonte: PHILIPS, 2009.

O gráfico 1 mostra que a lâmpada de vapor de mercúrio emite radiação ultravioleta e infravermelha.

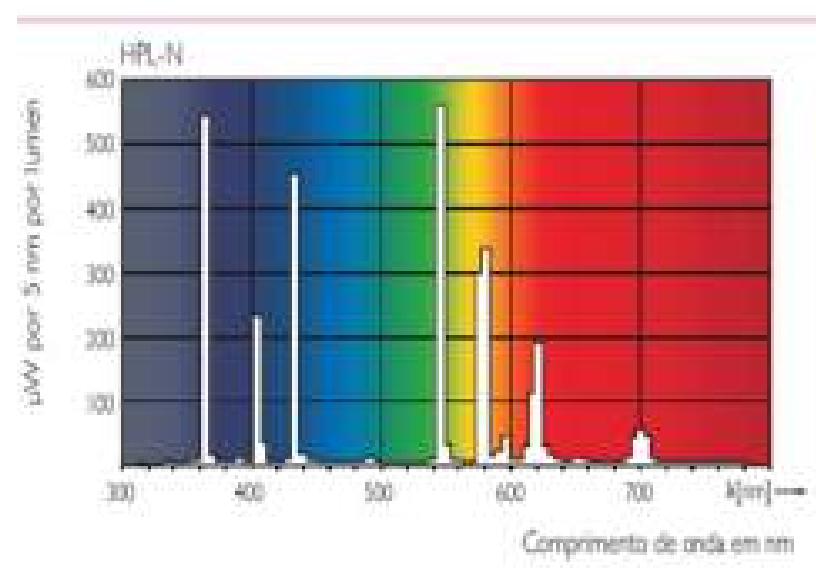

Gráfico 1 - Emissão de radiação ultravioleta e infravermelha pelas lâmpadas vapor de mercúrio. Fonte: PHILIPS, 2009.

\subsubsection{EMISSÃo de DIÓXIDO dE CARBono}

Ainda segundo APLIQUIM, a produção de energia elétrica emite $\mathrm{CO}_{2}$ para a atmosfera, seja por origem térmica ou hidrelétrica.

De acordo com o relatório "Emissões de dióxido de carbono e de metano pelos reservatórios hidrelétricos brasileiros" (Instituto Alberto Luiz Coimbra de PósGraduação e Pesquisa em engenharia COPPE, 2006), a emissão de $\mathrm{CO}_{2}$ para a atmosfera é de $24,573 \mathrm{~kg}$ por MW/h gerado. 
A substituição de 5 milhões de pontos de iluminação pública com lâmpadas vapor de mercúrio por lâmpadas LED reduziria $26.907,43$ t por ano de $\mathrm{CO}_{2}$ emitido para a atmosfera.

E com a substituição destas lâmpadas, o Brasil pode beneficiar-se com a venda dos créditos de carbono e obter $\$ 269.074,30$ por ano, supondo o preço de $\$ 10.00$ (em dólares americanos) por tonelada de CO2.

\subsection{ANÁlise dos BenEFícIos EnERgÉticos}

A lâmpada LED apresenta as seguintes características: boa cromaticidade, inibe a criminalidade e promove a valorização das áreas urbanas, do turismo do lazer noturno, destacando monumentos, prédios, praças, área de lazer e parques, contribuindo para o desenvolvimento social e econômico da cidade e facilitando a organização do sistema viário das cidades e eficiência energética.

Uma lâmpada incandescente transforma apenas 5\% da energia que consome em luz. Uma lâmpada a vapor de mercúrio aproxima-se dos $15 \%$, porém utilizando-se de vapor de mercúrio em seu interior. Os LEDs, por seu lado, têm taxas de eficiência entre $30 \mathrm{e}$ $50 \%$, dependendo da tecnologia com que são fabricados. A eficiência luminosa do LED é em torno de $80 \mathrm{Im} / \mathrm{W}$ enquanto da lâmpada de mercúrio é de $40,8 \mathrm{Im} / \mathrm{W}$.

O LED tem expectativa longa de vida mais de 50.000 horas, enquanto que a lâmpada de vapor de mercúrio tem em média 16.000 horas (PHILIPS, 2009), com isso há redução do custo de manutenção.

\subsubsection{LUMINOTÉCNICA}

O Índice de Reprodução de Cor (IRC) da lâmpada LED é 71 , enquanto que o da lâmpada de vapor de mercúrio é 40 , isto significa que enxergamos um objeto sob a luz da lâmpada LED com as cores mais próximas da luz natural do sol.

A poluição luminosa $(\mathrm{PL})$ é o efeito produzido pela luz exterior mal direcionada, que é dirigida para cima, ou para os lados, em vez de iluminar somente as áreas pretendidas, e invade locais próximos aos pontos de iluminação, acarretando em desconforto pela privação da escuridão absoluta.

A luz emitida para as regiões superiores e laterais reflete-se e difunde-se nas poeiras em suspensão no ar, tornando o céu noturno mais claro (VRUGT; VERWIMP, 1980), o que acontece com a lâmpada de vapor de mercúrio, pois a lâmpada LED emite luz na direção principal da região a ser iluminada, não ocasionando a poluição luminosa. As figuras 9 e 10 mostram a Distribuição de lluminância de ambas as lâmpadas.

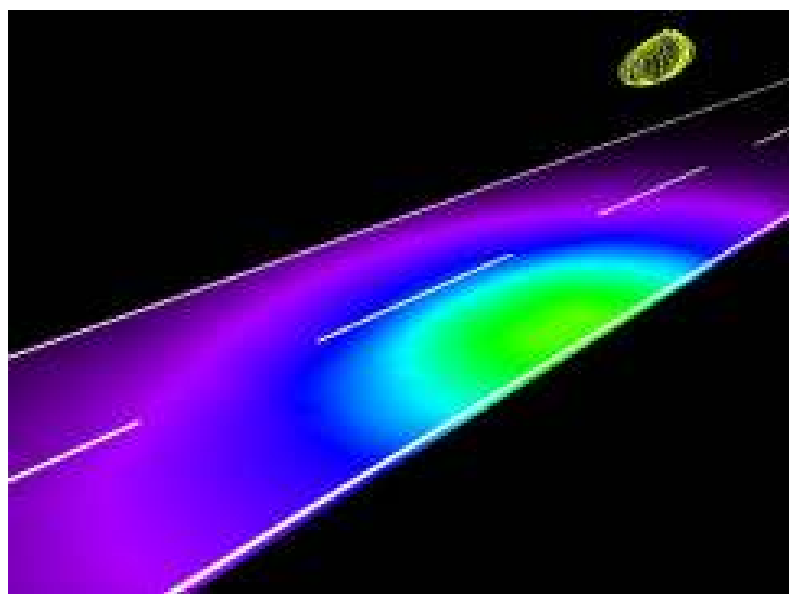

Figura 9 - Distribuição de lluminância da lâmpada LED $250 \mathrm{~W}$. Fonte: VRUGT; VERWIMP, 1980. 


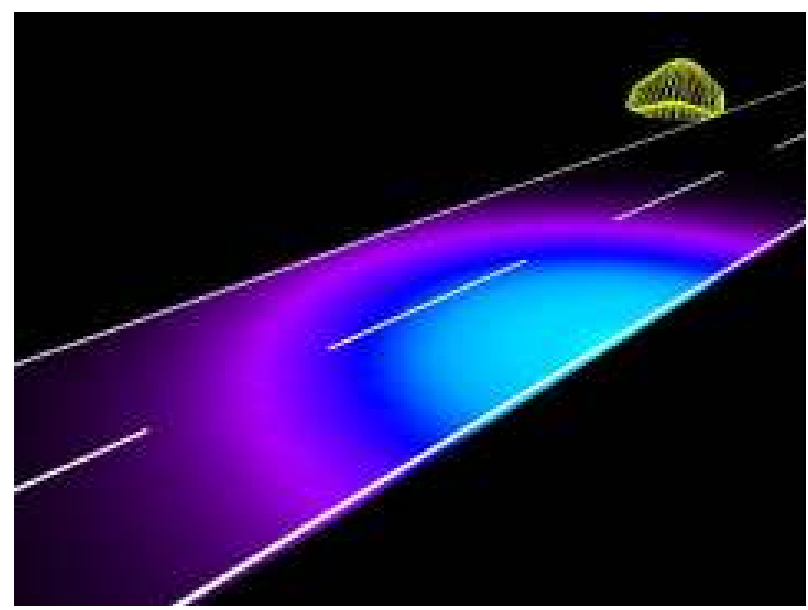

Figura 10 - Distribuição de lluminância da lâmpada Vapor de Mercúrio $250 \mathrm{~W}$.

Fonte: VRUGT; VERWIMP, 1980.

Um ensaio realizado no Laboratório de alta tensão, qualidade de energia e eficiência energética (LATQEEE) da Faculdade de Engenharia de Guaratinguetá (FEG - UNESP), utilizando um luxímetro Chroma meter CL-200 Konica MINOLTA, verificou-se a distribuição de luz de uma luminária LED em relação ao centro da mesma (Gráfico 2).

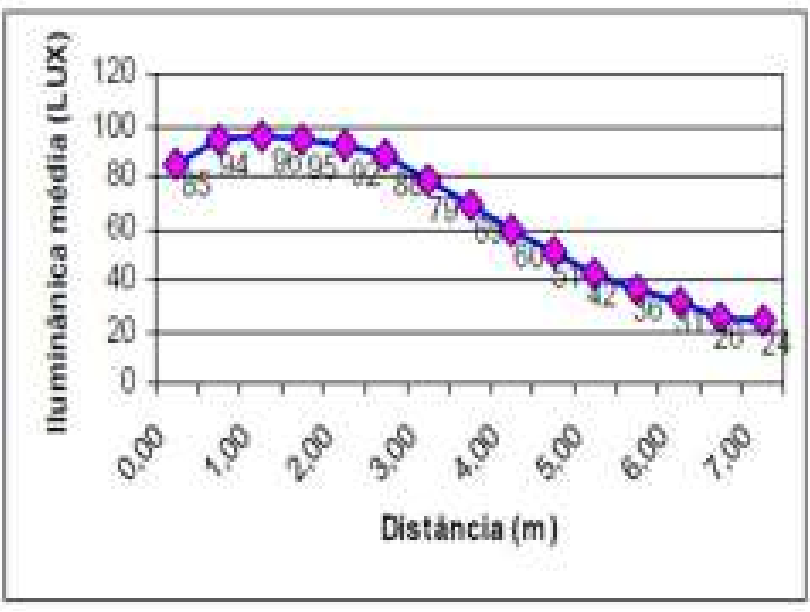

Gráfico 2 - Iluminância média. Fonte: FEG - UNESP, 2008.

Através do mesmo, constatou-se que para distâncias inferiores a 6,0 metros do centro da luminária, a iluminância média (Lux) atende à norma NBR 5101 (Associação Brasileira de Normas Técnicas, 2010), que trata da iluminância das vias para tráfego de veículos, de forma mais que satisfatória, tendo em vista que para vias de tráfego intenso a iluminância média mínima requerida é de 30 Lux (GIANELLI et al., 2009).

\section{Estudo de Caso}

\subsection{CRITÉRIOS EMPREgAdos nOS TESTES}

Segundo informações da ABNT, neste momento dá-se uma fase de transição da atual norma ABNT NBR 5101, atualizada pela última vez em 1992, e a nova NBR 5101, que está em fase de elaboração por uma comissão de estudos. Dessa forma, serão abordados os requisitos da norma em vigor sem deixar de lado as modificações e os conceitos que deverão ser introduzidos na revisão da norma, com o objetivo de deixá-la com padrões utilizados internacionalmente.

Além da norma brasileira, é comum as concessionárias e as prefeituras estabelecerem um manual de padronização para projetos de iluminação pública. Nestes manuais estão definidos os critérios de projeto e as condições específicas, levando em conta as características regionais, a padronização própria de materiais, entre outros aspectos.

A NBR 5101 estabelece uma classificação para os diversos tipos de vias, bem como uma classificação para o volume de tráfego nestas vias, e os respectivos critérios de iluminância.

As tabelas de 3 a 4 nos dão uma noção de como se classifica o tipo de via.

Com base nestas tabelas foi determinado o tipo de luminária mais adequada para substituição da iluminação existente. 
Tabela 3

Valores mínimos para os níveis médios de iluminância.

\begin{tabular}{|c|c|c|c|c|}
\hline \multirow{2}{*}{$\begin{array}{l}\text { Tipo de } \\
\text { via }\end{array}$} & \multicolumn{2}{|c|}{$\begin{array}{c}\text { Classificação do } \\
\text { trafego }\end{array}$} & \multirow{2}{*}{$\underset{\text { méd.min. }}{E}$} & \multirow{2}{*}{$\mathbf{U}$ min. } \\
\hline & Veiculo & Pedestre & & \\
\hline $\begin{array}{c}\text { Trânsito } \\
\text { rápido }\end{array}$ & \multirow{2}{*}{\multicolumn{2}{|c|}{ Qualquer }} & \multirow[t]{2}{*}{20} & 0,50 \\
\hline Arterial & & & & 0,30 \\
\hline \multirow{6}{*}{ Coletora } & \multirow{3}{*}{$\mathrm{L}$} & $\mathrm{L}$ & 2 & \multirow{6}{*}{0,20} \\
\hline & & M & 5 & \\
\hline & & 1 & 10 & \\
\hline & \multirow{3}{*}{ M } & $\mathrm{L}$ & 5 & \\
\hline & & M & 10 & \\
\hline & & I & 14 & \\
\hline \multirow{9}{*}{ Local } & \multirow{3}{*}{$\mathrm{L}$} & L & 2 & \multirow{9}{*}{0,20} \\
\hline & & M & 5 & \\
\hline & & 1 & 10 & \\
\hline & \multirow{3}{*}{ M } & L & 5 & \\
\hline & & M & 10 & \\
\hline & & I & 14 & \\
\hline & \multirow{3}{*}{ I } & L & 10 & \\
\hline & & M & 14 & \\
\hline & & 1 & 17 & \\
\hline Irregular & L & L & 2 & $\begin{array}{l}\text { Não é } \\
\text { fixado }\end{array}$ \\
\hline
\end{tabular}

Fonte: NBR 5101, 2012.

Tabela 4

Classificação da via.

\begin{tabular}{|c|c|}
\hline $\begin{array}{c}\text { Volume de tráfego } \\
\text { noturno de veículos, por } \\
\text { hora, em ambos os } \\
\text { sentidos, em pista única. }\end{array}$ & Leve \\
\hline $\begin{array}{c}\text { Pedestres cruzando vias } \\
\text { com trafego motorizado }\end{array}$ & Leve \\
\hline $\begin{array}{c}\text { Razão mínima entre } \\
\text { pontos de iluminância } \\
\text { adjacentes }\end{array}$ & 0,40 \\
\hline $\begin{array}{c}\text { E méd.min. } \\
\text { (lux) }\end{array}$ & 2 \\
\hline U min. & 0,20 \\
\hline
\end{tabular}

Fonte: Anglogold Ashanti, 2012.

\subsection{Procedimentos para Medição de ILUMINÂNCIA NA VIA}

As medições fotométricas de iluminâncias em um plano horizontal, nas proximidades do pavimento das vias públicas, apresentam um papel fundamental na determinação dos valores mínimos a serem considerados como resultado do cálculo da média aritmética das referidas iluminâncias, quando comparados com os dados contidos na Tabela 3. Essas medições devem ser realizadas tanto no caso de projetos novos quanto de reforma de pontos de iluminação pública.

Os procedimentos descritos na sequência foram tomados como referência, considerando que as luminárias estejam em funcionamento por pelo menos trinta minutos antecipadamente.

Como medida preventiva para uma eficaz realização das medições, foi providenciada a limpeza do elemento fotossensível do luxímetro, bem como sua aferição.

No momento da medição propriamente dito o luxímetro foi mantido em uma posição paralela ao piso da via de tráfego, a uma distância vertical aproximada de $15 \mathrm{~cm}$ acima de cada um dos pontos de medição marcados, anotando o valor encontrado em seu visor no espaço reservado da planilha.

Terminada a leitura em todos os pontos pertencentes à área de medição, foi encontrada a média aritmética dos valores coletados, obtendo-se finalmente a iluminância média para o espaçamento entre os postes adjacentes da via em questão.

Como cálculo complementar foi encontrado o valor do fator de uniformidade da iluminância $(U)$, mediante utilização da expressão matemática (3):

$\mathrm{U}=$ Emin./Eméd. 


\subsubsection{MÉtodos de CÁlculos PARA ILUMINAÇÃo PÚBLICA}

A iluminação pública é também uma iluminação de exterior, mas seu estudo envolve uma serie de particularidades, o que obriga a tratá-la de forma distinta. Um dos desafios da iluminação pública é obter a maior uniformidade entre os pontos de luz e a melhor reprodução de cores, com a melhor economia possível. Essas duas variáveis são opostas, logo se deve entender e trabalhar com as mesmas.

\subsubsection{ILUMINAÇÃo DE RUA}

Existem diferentes formas de disposição de luminárias e vias, mas para esta situação a distribuição unilateral se adequa convenientemente. De posse desta informação pode-se fixar os pontos a serem analisados. Como nesta avaliação 0 fator uniformidade é de extrema importância, logo foram determinados três pontos na mesma linha da luminária e três entre as luminárias, que assim totalizam seis pontos a serem estudados. Na Figura 11, são demostrados os pontos, através da vista superior.

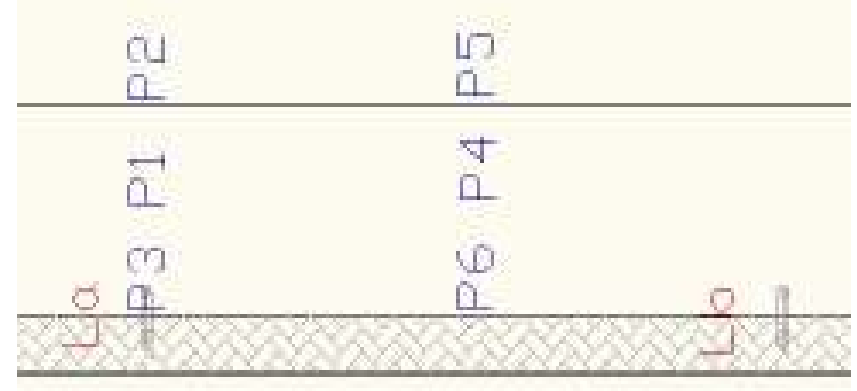

Figura 11 - Vista superior da rua. Fonte: ANGLOGOLD ASHANTI, 2012.
Na figura 12, pode-se observar a influência de cada luminária nos pontos onde se quer calcular a iluminância.

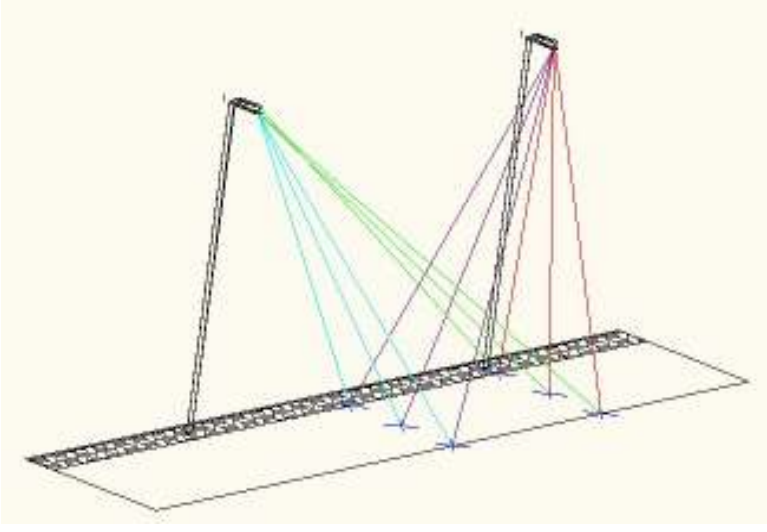

Figura 12 - Vista lateral da rua. Fonte: ANGLOGOLD ASHANTI, 2012.

Após as devidas verificações de área, foram necessários encontrar os valores de iluminância da via, para comparações, porem é necessário fazer a interpolação de dois pontos para chegar ao valor procurado. Em seguida, basta somar as contribuições das luminárias para obter a iluminância no ponto.

Para se encontrar as iluminância nos pontos referidos, utilizou-se um luxímetro como visto na Figura 13, da marca Instrutemp modelo ITLD260, lembrando que o mesmo estava devidamente calibrado.

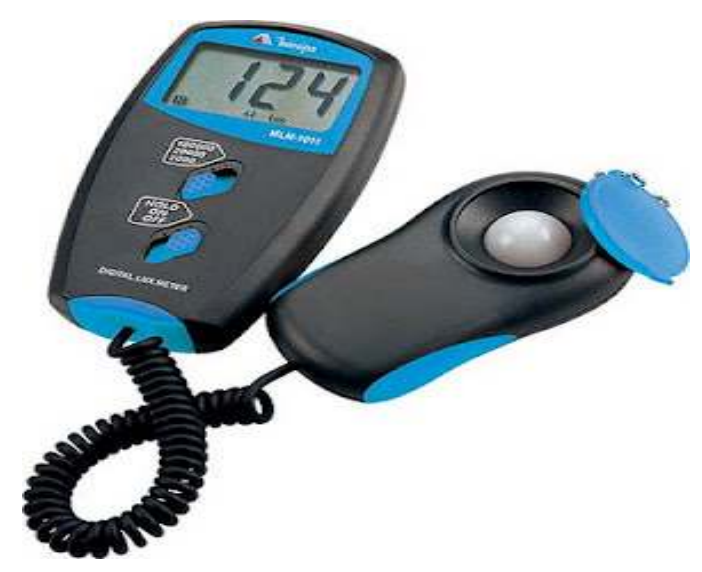

Figura 13 - Luxímetro. Fonte: ANGLOGOLD ASHANTI, 2012. 


\subsubsection{SitUAÇÃo EXISTENTE}

O nível de iluminamento atual foi mapeado de forma simples, com o objetivo de se ter a noção do nível médio de iluminância. Este valor 3,5 lux, será o ponto de partida para os estudos de alternativas de revitalização.

Após estudo feito na via, constatou-se a existência dos seguintes materiais utilizados:

- Via de 9m de largura de duplo sentido;

- Distância entre postes de $42 \mathrm{~m}$.

- Postes de concreto de $10 \mathrm{~m}$ do tipo duplo T;

- Braço de metal de 3m de comprimento;

- Luminárias em alumínio com defletores em acrílico;

- Lâmpadas Vapor de Mercúrio de 125 W;

- Reatores para lâmpadas vapor de mercúrio de $125 \mathrm{~W}$;

\subsubsection{Testes Efetuados}

As tabelas 5 e 6 mostram os resultados das medições de iluminância em lux.

Com base nestes dados, constataram-se algumas discrepâncias entre os valores obtidos nas medições e cálculos com os dados do fabricante. De acordo com catalogo da OSRAM, fabricante da lâmpada atualmente instalada, a iluminância de uma lâmpada vapor de mercúrio $125 \mathrm{~W}$, é de $6300 \mathrm{~lm}$.
Tabela 5

lluminância medidas para lâmpadas VM 125 W.

\begin{tabular}{|lllll|}
\hline & $\begin{array}{l}\text { Eixo } \\
\text { Pista }\end{array}$ & $\begin{array}{l}\text { da } \\
\text { Externa da } \\
\text { Pista }\end{array}$ & $\begin{array}{l}\text { Lateral } \\
\text { Interna da } \\
\text { Pista }\end{array}$ \\
\hline Luminárias & P1 & P2 & P3 \\
\hline La & 5 & 2 & 4 \\
\hline Lb & 2 & 0 & 1 \\
\hline Luminárias & P4 & P5 & P6 \\
\hline La & 0 & 0 & 0 \\
\hline Lb & 2 & 0 & 1 \\
\hline Iluminância Média & 3,5 & \\
\hline
\end{tabular}

Fonte: ANGLOGOLD ASHANTI, 2012.

Tabela 6

lluminância medidas para luminária LED 89 W.

\begin{tabular}{|l|lll|}
\hline & $\begin{array}{l}\text { Eixo } \\
\text { Pista }\end{array}$ & $\begin{array}{l}\text { dateral } \\
\text { Externa da } \\
\text { Pista }\end{array}$ & $\begin{array}{l}\text { Lateral } \\
\text { Interna da } \\
\text { Pista }\end{array}$ \\
\hline Luminárias & P1 & P2 & P3 \\
\hline La & 21 & 16 & 20 \\
\hline Lb & 4 & 3 & 3 \\
\hline Luminárias & P4 & P5 & P6 \\
\hline La & 7 & 6 & 6 \\
\hline Lb & 7 & 6 & 6 \\
\hline Iluminância Média & 18,5 & \\
\hline
\end{tabular}

Fonte: ANGLOGOLD ASHANTI, 2012. 
De posse destes dados, foi utilizada a fórmula abaixo para encontrar a iluminância referente ao que dizia o catálogo $(6300 \mathrm{Im})$, no entanto, o valor encontrado foi de $3200 \mathrm{Im}$, metade do que sugeria o fabricante. Se for levado em consideração o valor medido com o luxímetro, a iluminância cairá ainda mais para (2240 Im). Nesse caso, deve-se levar em conta o fato da luminária possuir lente de policarbonato transparente e, mesmo sendo limpa anteriormente, sua vida útil já desgastada, prejudica visivelmente o desempenho da lâmpada, reduzindo assim seu fluxo luminoso.

Já para a luminária LED a iluminância encontrada foi de 18,5 lux, quase 3 vezes maior que o sistema antigo, o que representa uma eficiência luminosa de $67 \%$.

Para encontrar a iluminância atual do ponto foi utilizada a Eq. 4:

$$
\emptyset=\frac{S \times F}{F u \times F d}
$$

onde:

$\mathrm{S}$ - área a iluminar em $\mathrm{m}^{2}$.

E - lluminamento requerido em lux.

$\varnothing$ - fluxo necessário em Im.

E sabendo que os fatores de utilização e depreciação serão escolhidos conforme:

- Fu - Fator de utilização é igual a:

- 1 - se todo o fluxo cai sobre a área a iluminar.

○ $\quad 0,75$ - se mais de $50 \%$ do fluxo cai sobre a área a iluminar.
- 0,60 - de $25 \%$ a $50 \%$ do fluxo caem sobre a área a iluminar.

- 0,40 - menos de $25 \%$ do fluxo caem sobre a área a iluminar.

- Fd- Fator de depreciação é igual a:

- 0,65 para refletores / luminárias abertas.

- 0,75 para refletores / luminárias fechadas.

\subsection{Resultados}

A tabela 7 retrata um comparativo entre os resultados reais obtidos como base das medições de iluminância.

Tabela 7

Tabela Comparativa após os testes.

\begin{tabular}{lll}
\hline & $\begin{array}{l}\text { Vapor de } \\
\text { Mercúrio 125W }\end{array}$ & LED 89W \\
\hline $\begin{array}{l}\text { Potencia média } \\
\text { de consumo }\end{array}$ & $125 \mathrm{~W}$ & $89 \mathrm{~W}$ \\
\hline $\begin{array}{l}\text { Fluxo luminoso } \\
\text { Eficiência }\end{array}$ & $2240 \mathrm{Im}$ & $\begin{array}{l}6000-6800 \\
\mathrm{Im}\end{array}$ \\
\hline $\begin{array}{l}\text { Luminosa } \\
\text { Temperatura da }\end{array}$ & $418 \mathrm{I} / \mathrm{w}$ & $\sim 75 \mathrm{I} / \mathrm{w}$ \\
\hline Vida Útil & $\sim 10000 \mathrm{~h}$ & $\sim 50000 \mathrm{~h}$ \\
\hline IRC & $\sim 45$ & $5700-6500 \mathrm{~K}$ \\
\hline
\end{tabular}

Fonte: ANGLOGOLD ASHANTI, 2012. 
A perda de eficiência relativa à vida útil de uma lâmpada vapor de mercúrio chega a ser $64 \%$, um índice altíssimo quando levado em consideração a eficácia do sistema, e principalmente a segurança que se faz necessária numa via publica.

Mediante a isso, fica claro na tabela 8 , o ganho obtido com o uso da tecnologia LED.

Tabela 8

Ganhos relativos á tecnologia LED.

\begin{tabular}{|c|c|c|}
\hline Descrição & LED & $\begin{array}{l}\text { Vapor de } \\
\text { Mercúrio }\end{array}$ \\
\hline $\begin{array}{l}\text { Consumo de } \\
\text { energia mensal } \\
(\mathrm{MW} / \mathrm{h})\end{array}$ & $1,015 \mathrm{MW} / \mathrm{h}$ & $1,501 \mathrm{MW} / \mathrm{h}$ \\
\hline $\begin{array}{l}\text { Consumo de } \\
\text { energia anual } \\
(\mathrm{MW} / \mathrm{h})\end{array}$ & $12 \mathrm{MW} / \mathrm{h}$ & $18 \mathrm{MW} / \mathrm{h}$ \\
\hline $\begin{array}{l}\text { Economia de } \\
\text { energia anual } \\
(\mathrm{MW} / \mathrm{h})\end{array}$ & \multicolumn{2}{|c|}{$6 \mathrm{MW} / \mathrm{h}$} \\
\hline $\begin{array}{c}\text { Consumo de } \\
\text { energia em 50.000h } \\
(M W / \mathrm{h})\end{array}$ & $140 \mathrm{MW} / \mathrm{h}$ & $207 \mathrm{MW} / \mathrm{h}$ \\
\hline $\begin{array}{c}\text { Economia em } \\
50.000 \mathrm{~h}(\mathrm{MW} / \mathrm{h})\end{array}$ & \multicolumn{2}{|c|}{$67 \mathrm{MW} / \mathrm{h}$ ou $32,4 \%$} \\
\hline $\begin{array}{c}\text { Custo mensal com } \\
\text { energia } \\
\text { Sendo } R \$ 0,18 \\
\text { KW/h }\end{array}$ & $\mathrm{R} \$ 182,74$ & $R \$ 270,22$ \\
\hline $\begin{array}{l}\text { Economia Mensal } \\
\text { (R\$) }\end{array}$ & \multicolumn{2}{|c|}{$\mathrm{R} \$ 87,48$} \\
\hline $\begin{array}{l}\text { Custo anual com } \\
\text { energia (R\$) }\end{array}$ & $R \$ 2.192,83$ & $R \$ 3.242,59$ \\
\hline $\begin{array}{l}\text { Economia Anual } \\
\text { (R\$) }\end{array}$ & \multicolumn{2}{|c|}{$\mathrm{R} \$ 1.049,76$ ou $32,4 \%$} \\
\hline $\begin{array}{l}\text { Custo da energia } \\
\text { em } 50.000 \mathrm{~h}(\mathrm{R} \$)\end{array}$ & $\mathrm{R} \$ 25.380,00$ & $\mathrm{R} \$ 37.530,00$ \\
\hline $\begin{array}{l}\text { Economia em } \\
50.000 h(R \$)\end{array}$ & \multicolumn{2}{|c|}{$\mathrm{R} \$ 12.150,00$} \\
\hline $\begin{array}{c}\text { Trocas em } 50.000 \mathrm{~h} \\
\text { ou } 11 \text { anos } \\
\text { (12h/dia) }\end{array}$ & 0 & 3,5 \\
\hline $\begin{array}{l}\text { Custo da } \\
\text { Instalação }\end{array}$ & $\mathrm{R} \$ 54.000,00$ & $R \$ 9.000,00$ \\
\hline $\begin{array}{l}\text { Custo total de } \\
\text { Instalação }\end{array}$ & $\mathrm{R} \$ 25.434,00$ & $\mathrm{R} \$ 37.540,00$ \\
\hline
\end{tabular}

Fonte: ANGLOGOLD ASHANTI, 2012.
Os gráficos 3 e 4 ilustram de forma simplificada o consumo, e a economia inerentes ao uso da tecnologia LED.

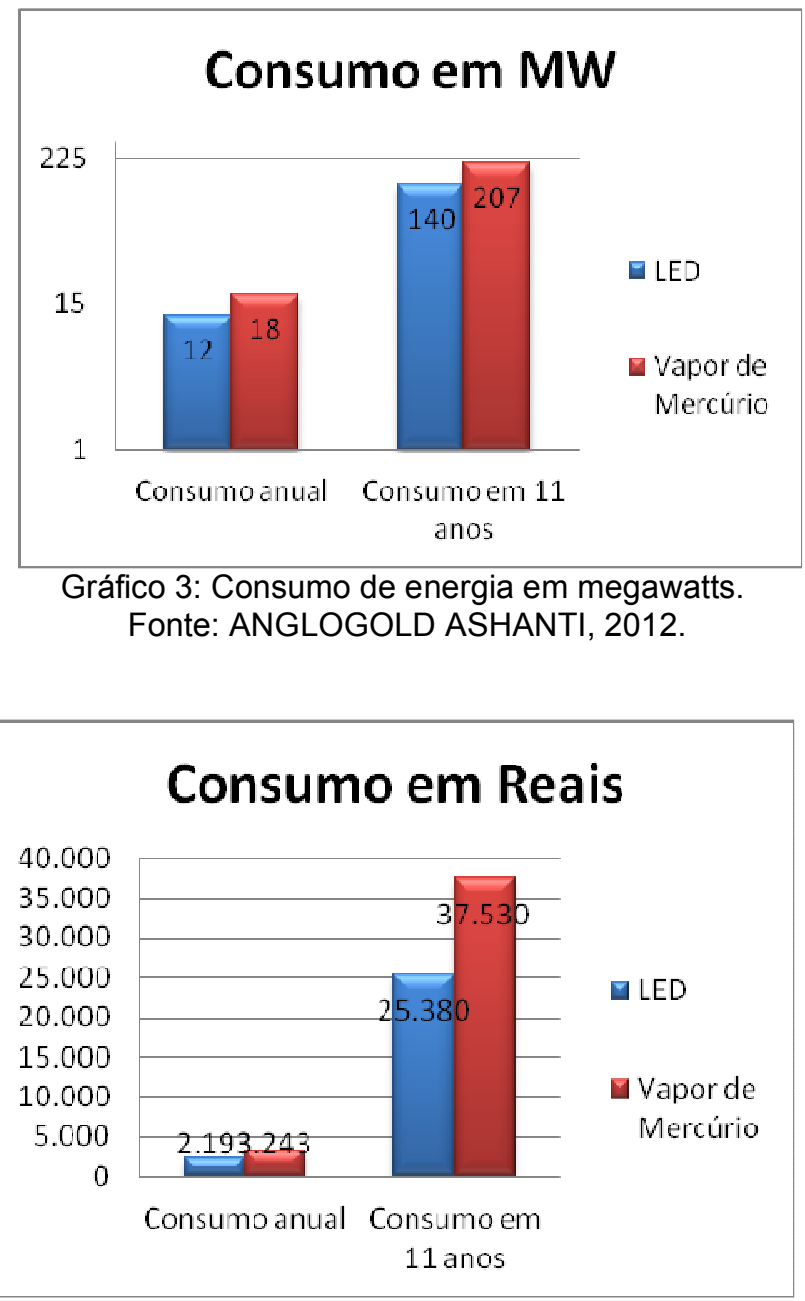

Gráfico 4: Consumo de energia em milhões de reais. Fonte: ANGLOGOLD ASHANTI, 2012.

\subsubsection{MATERIAL UTILIZADO NA SUBSTITUIÇÃO}

Tendo em vista o alto custo ainda empregado, relativo a essa tecnologia, foi feita uma pesquisa com diversos tipos de luminárias LED, de diversos fabricantes. Levando-se em consideração o seu custo beneficio, a luminária que apresentou melhores resultados foi a High Power Modular Street Light - HP MSL, da OSRAM.

e-xacta, Belo Horizonte, v. 5, n. 1, p. 111-132. (2012). Editora UniBH. Disponível em: www.unibh.br/revistas/exacta/ 
O modelo escolhido devido às características existentes da via foi High Power Modular Street Light 4.

\subsubsection{ESPECIFICAÇÕES}

A seguir na tabela 9 é possível verificar as especificações da luminária utilizada para testes.

Tabela 9

Especificações da luminária.

\begin{tabular}{|c|c|c|}
\hline Caracteristica & Parâmetro & HP MSL - 4 \\
\hline \multirow{6}{*}{ Iluminação } & $\begin{array}{c}\text { Fluxo } \\
\text { Luminoso }\end{array}$ & $6000-6800 \mathrm{~lm}$ \\
\hline & $\begin{array}{l}\text { Potencia } \\
\text { Nominal }\end{array}$ & $89 W$ \\
\hline & Eficiência & $67-76 \mathrm{~lm} / \mathrm{W}$ \\
\hline & $\begin{array}{c}\text { Temperatura } \\
\text { da Cor }\end{array}$ & $5700-6500 \mathrm{~K}$ \\
\hline & IRC & $\sim 70$ \\
\hline & Vida Útil & $>50.000$ horas \\
\hline \multirow{3}{*}{ Elétrica } & Tensão & $100-240$ VCA \\
\hline & $\begin{array}{l}\text { Corrente } \\
\text { Máxima }\end{array}$ & $10 \mathrm{~A}$ \\
\hline & $\begin{array}{l}\text { Fator de } \\
\text { Potência }\end{array}$ & $>0,9$ \\
\hline \multirow{3}{*}{ Mecânica } & Manutenção & $\begin{array}{l}\text { Tanto o driver como } \\
\text { o módulo LED } \\
\text { podem ser trocados } \\
\text { independentemente }\end{array}$ \\
\hline & Óptica & $\begin{array}{l}\text { Refletor com } \\
\text { revestimento em } \\
\text { policarbonato }\end{array}$ \\
\hline & Peso & $14 \mathrm{Kg}$ \\
\hline
\end{tabular}

Fonte: OSRAM, 2012.
High Power Modular Street Light é uma luminária urbana de ultima geração com módulos de LED manejáveis, que permitem configurações flexíveis em diferentes aplicações. Substitui as luminárias tradicionais HQI/HPS com 70-250W. Com sua construção robusta, alto sistema de eficácia e ótimo design óptico, a luminária possui uma longa vida útil com notável redução na emissão de $\mathrm{CO}_{2}$ e poluição luminosa como pode ser conferido na Tabela 9.

\subsubsection{Benefícios e CaRACterísticas}

- Alta eficiência óptica

Eficiência Óptica de 92\% e distribuição assimétrica que otimizam a incidência de luz na área alvo, como mostrado na Figura 16

- Nível de Proteção

IP66 - Indicado para uso externo, Figura 17.

- Módulos HPML substituíveis

Luminária fixa e módulos HPML substituíveis que simplificam a manutenção e atualização do sistema, como mostrado nas figuras 14 e 15.

- Alta eficiência Energética

Sistema de eficácia de 67-77 Im/W economiza mais de $50 \%$ de energia comparativamente às luminárias clássicas.

- Meio Ambiente

Livre de materiais perigosos.

- Vida útil longa

Otimizado para vida útil longa e manutenção da iluminância no decorrer da mesma.

- $\quad$ RRC e Visibilidade 
Alta visibilidade para facilitar o reconhecimento de cores e objetos à noite.

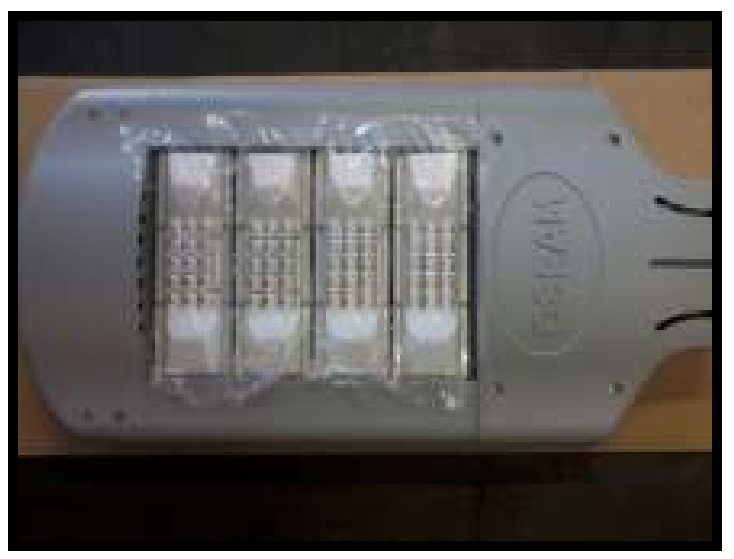

Figura 14 - Luminária LED - High Power Modular Street Light - 4.

Fonte: ANGLOGOLD ASHANTI, 2012.

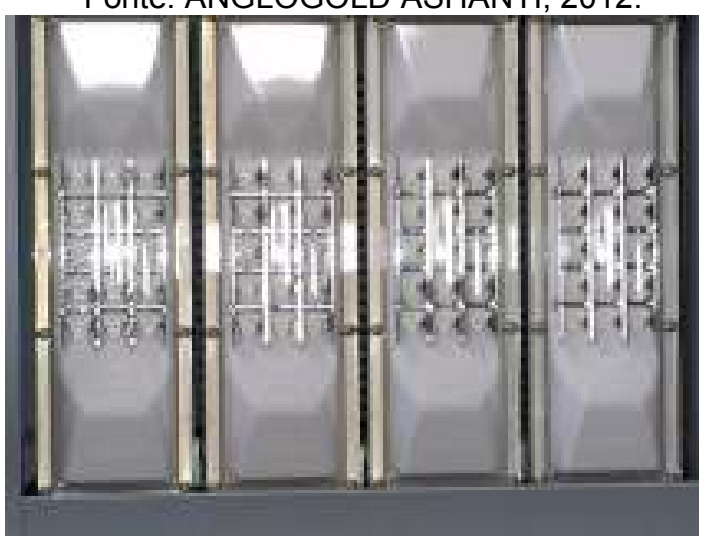

Figura 15 - Luminária LED - Formada por 4 módulos em paralelo.

Fonte: ANGLOGOLD ASHANTI, 2012.

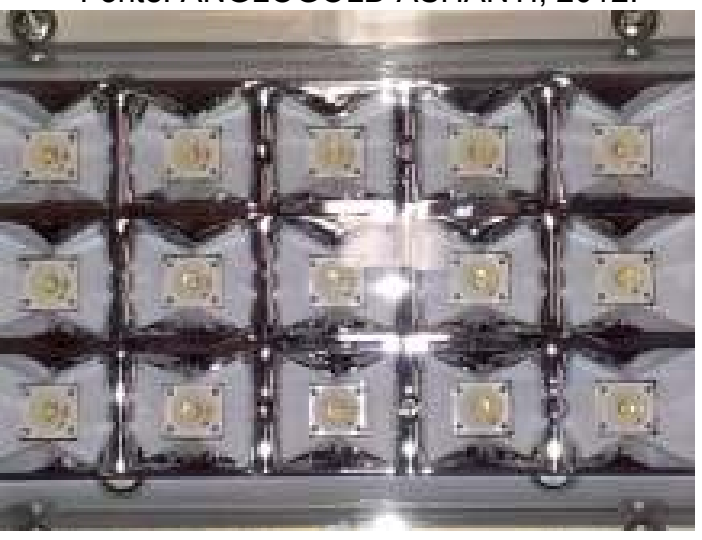

Figura 16 - Arranjo com 15 LEDs por módulo. Fonte: ANGLOGOLD ASHANTI, 2012.

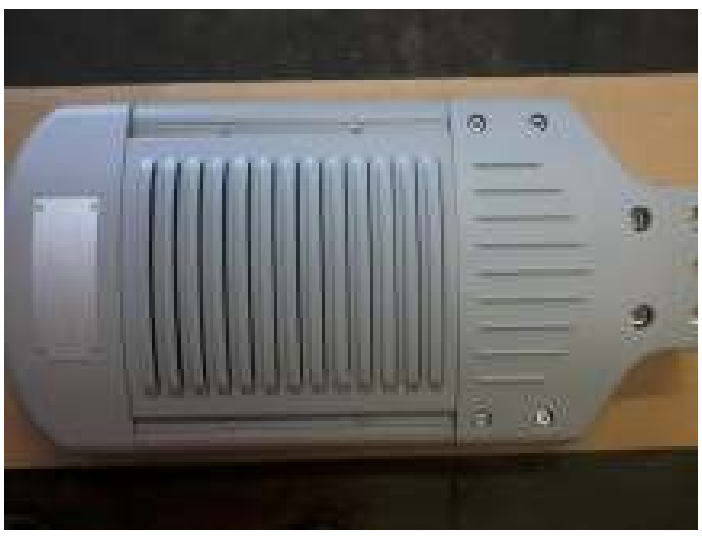

Figura 17 - Aletas para circulação de ar, e resfriamento dos módulos.

Fonte: ANGLOGOLD ASHANTI, 2012.

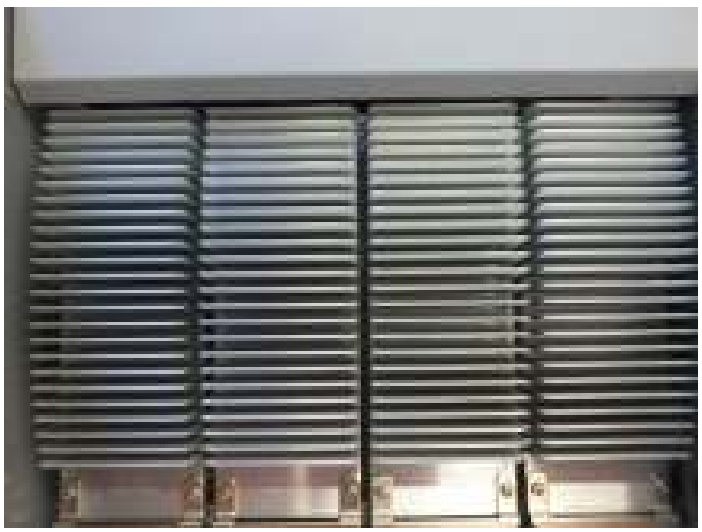

Figura 18 - Dissipador de calor acoplado com cada módulo.

Fonte: ANGLOGOLD ASHANTI, 2012.

$\mathrm{Na}$ figura 18, é apresentado um sistema para dissipação de calor, que fica instalado em cada módulo, aumentando ainda mais a eficiência da luminária.

\subsubsection{ESPECIFICAÇõES DO DRIVER}

Para o acionamento da luminária, faz-se necessário o uso de um driver, mostrado na Figura 19, que tem seu funcionamento similar ao de um reator convencional,

e-xacta, Belo Horizonte, v. 5, n. 1, p. 111-132. (2012). Editora UniBH. Disponível em: www.unibh.br/revistas/exacta/ 
porém suas características são específicas para módulos eletrônicos.

A tabela 10 apresenta algumas das especificações do driver utilizado nesta luminária, que é fabricado Mean Well. Maiores detalhes podem ser vistos no APENDICE 2.

Tabela 10

Especificações do Driver.

\begin{tabular}{|c|c|c|}
\hline \multicolumn{2}{|c|}{ Modelo } & CLG-150-24 \\
\hline \multirow{3}{*}{ Saída } & Tensão & $24 \mathrm{VDC}$ \\
\hline & Corrente & $6,3 \mathrm{~A}$ \\
\hline & Potência & $151,2 \mathrm{~W}$ \\
\hline \multirow{4}{*}{ Entrada } & Tensão & $90 \sim 295$ VCA \\
\hline & Corrente & $1 \mathrm{~A} / 230 \mathrm{~V}$ \\
\hline & Fator de & $>0,95 / 230 \mathrm{~V}$ \\
\hline & Rendimento & $88 \%$ \\
\hline \multicolumn{2}{|c|}{ Grau de Proteção } & IP 67 \\
\hline
\end{tabular}

Fonte: MEAN WELL, 2012.

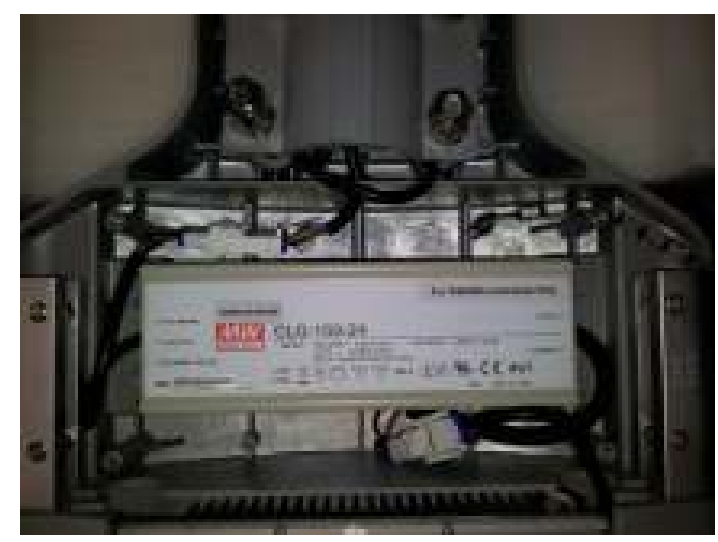

Figura 19 - Driver de acionamento.

Fonte: ANGLOGOLD ASHANTI, 2012.

\section{ConClusÃo}

Após a realização de pesquisas com as luminárias apresentadas neste trabalho, foi elaborado um estudo luminotécnico e econômico para comparar o consumo de energia elétrica entre as luminárias estudadas.

Lembrando que o consumo diário para iluminação pública na empresa é de 12 horas e a vida estimada de uma luminária LED é de 50.000 horas, conclui-se que o tempo de operação desta luminária será de 11,5 anos. Tendo em vista que uma luminária com lâmpada Vapor de Mercúrio $125 \mathrm{~W}$, operando nas mesmas condições, 12 horas/dia, com vida mediana de 9.000 horas resultará somente em 1,8 anos de operação. 0 que acarretará em 3,5 trocas a mais, quando usado o período de uma luminária a LED.

A economia de energia obtida neste processo anualmente será de $6 \mathrm{MW} / \mathrm{h}$, isso representa uma economia em valores da ordem de $\mathrm{R} \$ 1.049,76$. Se for levada em consideração, para fins de comparação, a vida útil da luminária LED, que tem em média 11 anos, a empresa terá economizado em consumo, cerca de $67 \mathrm{MW} / \mathrm{h}$ ou $\mathrm{R} \$ 12.150,00$ o que equivale a $32,4 \%$ de economia em relação ao sistema de iluminação atual. Uma quantia bastante significativa, levando-se em conta que se trata apenas da iluminação publica em um determinado trecho.

\section{CONSIDERAÇÕES FINAIS}

A tecnologia dos LEDs vem ganhando espaço e deixando de ser apenas um sinalizador (LigadoDesligado) em equipamentos, sendo usada para iluminação decorativa, veículos automotivos, iluminação pública, entre outras áreas. 
Vale ressaltar a sua capacidade de atingir altos níveis de fluxo luminoso, com menor consumo de energia elétrica, apresentando alta durabilidade e robustez.

O conjunto de LEDs nas luminárias é capaz de atingir os níveis necessários de fluxo luminoso a ser implementado na iluminação pública. Apesar do elevado custo de implementação a tecnologia pode ser aplicada, pois o retorno do investimento viabiliza o projeto.
O uso das luminárias LEDs já é uma realidade em algumas cidades de países com poderio econômico elevado e vem aos poucos ganhando espaço também nas cidades brasileiras. O uso desta tecnologia, como alternativa de recurso energético no Brasil, proporcionará economia de energia elétrica em nossas usinas hidrelétricas, contribuindo para que não haja o risco de um "Novo Apagão".

\section{REFERÊNCIAS}

ABNT - NBR 5101: lluminação Pública. Belo Horizonte, MAIO, 2012. 18 p.

ANGLOGOLD ASHANTI, Disponível em http://www.anglogoldashnati.com.br. Acesso em: 20 mai. 2012.

APLIQUIM, O uso de mercúrio em lâmpadas e o risco de sua disposição inadequada, MAIO, 2009.

BRABER, W.. LED working principles, electric, thermal and optical characteristics. 2007, p. 22.

ELETROBRAS, Disponivel em http://www.eletrobras.gov.br/elb/procel/main.asp.

Acesso em: 20 ago. 2011.

GIANELLI B F, SILVEIRA M C F, THAUMATURGO L R Y, ASTORGA O A M, FILHO M B M.. O Emprego de Tecnologia LED na Iluminação Pública - Seus Impactos na Qualidade de Energia e no Meio Ambiente. The 8th latin american congress on electricity generation and transmission - CLAGTEE, 2009.

LATQEEE - Faculdade de Engenharia de Guaratinguetá (FEG - UNESP), OUT, 2008, p. 15.

MAGHE, L.. Practical experience using LED for lighting and signage product, 2007, p.72.

MEAN WELL, Catalogo de Produtos. Disponível em $<$ http://www.meanwell.com>. Acesso em: 14 abr. 2012.

MINOLTA, The Language of Light. Disponível em <http://www.minolta.com>. Acesso em: 5 abr. 2012.
NEARY, Michael; QUIJANO, M., Solid state Lighting for Industrial Locations. Disponível em <http://www.ieeexplore.org>. Acesso em: 05 abr. 2012.

OSRAM: Catalogo de produtos. Disponível em <http://www.osram.com.br/osram br/Ferramentas \%2 6 Catlogos/index.html >. Acesso em: 15 maio. 2012.

P. HANSALER, Optical Characterization of Leds, 2007, p.112.

PHILIPS. Lâmpadas de descarga de Alta Intensidade (H.I.D) HPL-N (Vapor de Mercúrio): catálogo, Brasil, 2009, p. 2.

SANTOS, V. E. G. d., Tipos de Lâmpadas, Departamento de Engenharia Eletrotécnica Escola Superior de Tecnologia de Viseu, vol. 2. 2005. Disponível em http://www.estv.ipv.pt/PaginasPessoais/vasco/textos/F ontes Lumin.pdf Acesso em:12 mar. 2012.

SCHUBERT, E. R. Light-Emitting Diodes. Cambridge: University Press, 2003.

TSAO, J. Y. Solid State Lighting: Lamps, Chips and Materials for Tomorrow. IEEE Circuits\&Devices, vol. 20, n. 3 , p. $28-37$.

VRUGT, J.W.; VERWIMP, J.K.P.. High pressure mercury vapour lamps. 1980, p. $37-38$.

WHITAKER, T.. On the verge: LEDs are ready to challenge incumbent light sources in the street lighting market, LEDs Magazine Review, Out. 2006, issue 9, p. 11-13.

e-xacta, Belo Horizonte, v. 5, n. 1, p. 111-132. (2012). Editora UniBH. Disponível em: www.unibh.br/revistas/exacta/ 
ŽUKAUSKAS, A.; SHUR, M. S.; GASKA, R. Introduction to Solid-StateLighting.2002, p. 29.

e-xacta, Belo Horizonte, v. 5, n. 1, p. 111-132. (2012). Editora UniBH.

Disponível em: www.unibh.br/revistas/exacta/ 